\title{
BRIEF COMMUNICATIONS
}

\section{EARLY FAILURE OF FREEHAND AORTIC STENTLESS XENOGRAFT VALVES}

\author{
Giovanni Battista Luciani, MD, Paolo Bertolini, MD, and Alessandro Mazzucco, MD, Verona, Italy
}

The evidence of suboptimal hemodynamics and of limited durability of stented porcine bioprostheses has promoted a revived interest in stentless xenografts for aortic valve replacement. ${ }^{1,2}$ Like freehand aortic allografts, stentless bioprostheses adapt to the aortic root to mimic the anatomy of the native valve. This property is expected to allow for reduced mechanical stress on the valve leaflets, thereby controlling calcific degeneration of the xenograft, and for improved hemodynamics, possibly affecting clinical outcome after aortic valve replacement. ${ }^{1,2}$ However, as the experience gathered with stentless xenografts is recent and a variety of models has been introduced in the clinical practice, close monitoring of the shortcomings of these prostheses is warranted.

Clinical summaries

PATIENT 1. A 72-year-old woman with moderate aortic valve stenosis, severe regurgitation, and coronary artery disease underwent valve replacement with an O'BrienAngell (Bravo Cardiovascular Model 300, CryoLife, Inc., Atlanta, Ga.) stentless porcine valve and myocardial revascularization with two coronary artery bypass grafts. A size 25 Bravo xenograft was sutured in a supraanular, infracoronary position with three running sutures of 3-0 Prolene polypropylene (Ethicon, Inc., Somerville, N.J.) as described by O'Brien. ${ }^{3}$ The postoperative course of the patient was marked by circulatory instability necessitating 2 days of ventilation and inotropic support. The patient was discharged on the tenth postoperative day, with echocardiographic evidence of mild central regurgitation of the prosthesis. Six months later the patient started having recurrent effort dyspnea. A second echocardiogram and angiogram showed moderate-to-severe aortic prosthetic valve regurgitation. At reoperation, 8 months after the original procedure, the xenograft valve leaflets were intact. The porcine aortic wall support of the valve, however, was torn for a length of about $1 \mathrm{~cm}$ at the level of the native noncoronary cusp, causing severe perivalvular regurgitation (Fig. 1). The stentless valve was replaced with a size 25 Hancock II (Hancock Extracorporeal Inc., Anaheim, Calif.) stented xenograft. The postoperative

From the Division of Cardiac Surgery, University of Verona, Verona, Italy.

Received for publication June 28, 1996; accepted for publication Oct. 24, 1996.

Address for reprints: Giovanni Battista Luciani, MD, Division of Cardiac Surgery, University of Verona, O. C. M. Piazzale Stefani 1, Verona, 37126, Italy.

J Thorac Cardiovasc Surg 1997;113:1109-10

Copyright (C) 1997 by Mosby-Year Book, Inc.

$0022-5223 / 97 \$ 5.00+0 \quad \mathbf{1 2 / 5 4 / 7 8 9 3 0}$ recovery of the patient was uneventful, with echocardiographic evidence of satisfactory prosthetic valve function at discharge.

PATIENT 2. A 61-year-old woman with critical aortic stenosis (peak pressure gradient of $120 \mathrm{~mm} \mathrm{Hg}$ ) underwent valve replacement with a size 23 O'Brien-Angell stentless porcine xenograft, as described above. ${ }^{3}$ At discharge, on the sixth postoperative day, the echocardiographic function of the aortic prosthesis (peak pressure gradient of $4 \mathrm{~mm} \mathrm{Hg}$ ) was satisfactory. Five months after the operation, the patient started having chest pain and dyspnea. Doppler echocardiography disclosed a significant transprosthetic pressure gradient $(36 \mathrm{~mm} \mathrm{Hg}$ ). Five months later, during a hospital admission for further diagnostic workup, the patient had an episode of syncope. A second catheterization revealed severe prosthetic valve obstruction (peak pressure gradient of $82 \mathrm{~mm} \mathrm{Hg}$ ) caused by restricted motion of the valve leaflets. At reoperation, 11 months after implantation of the stentless bioprosthe-

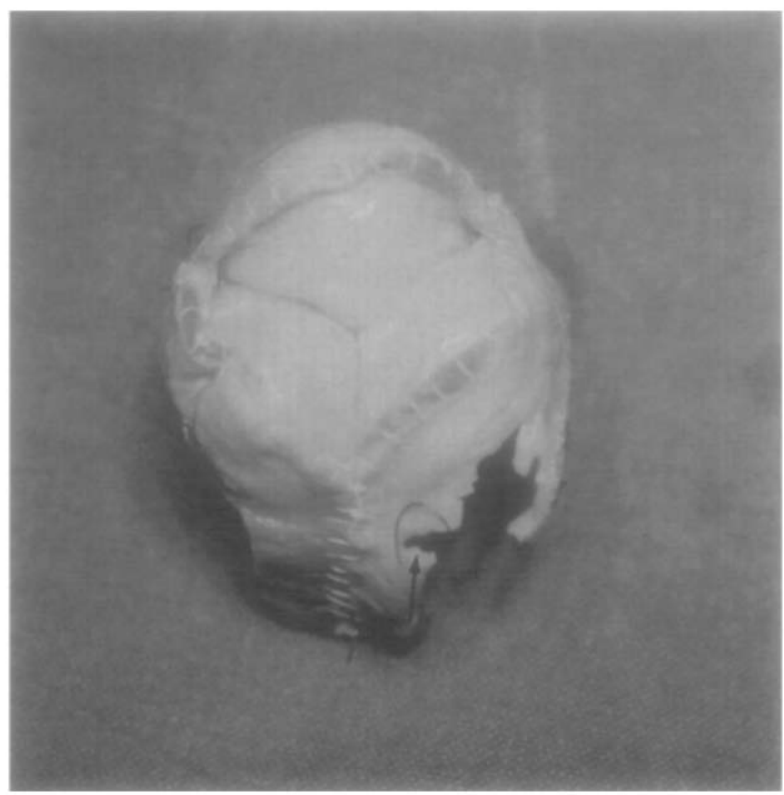

Fig. 1. Postoperative upside-down view of the explanted xenograft in patient 1 , showing the torn porcine aortic wall support of the valve. The original $5 \mathrm{~mm}$ long tear at the level of right noncoronary commissural pillar is evident (arrow). The larger tear at the base of the noncoronary cusp was produced during explantation of the xenograft. The valve leaflets are otherwise intact. 


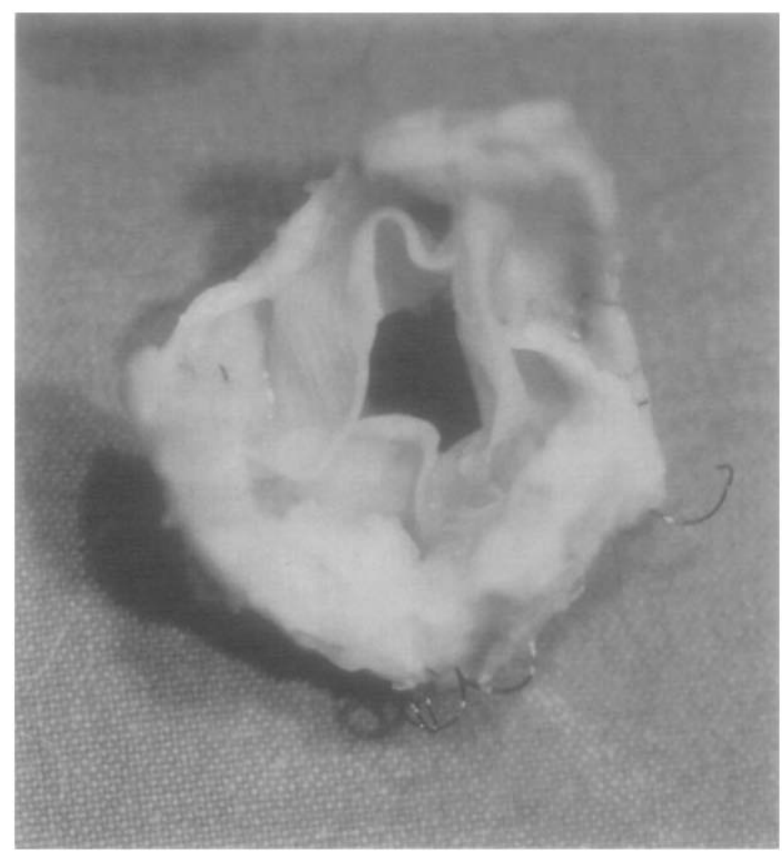

Fig. 2. Postoperative view of the explanted xenograft in patient 2. Distortion and stiffening of the valve leaflets owing to pannus, which fills two of the three valve cusps, is evident.

sis, the aortic root and valve leaflets were found to be extensively covered and distorted by fibrous tissue overgrowth (Fig. 2). Because of scarring, the aortic anulus was too narrow for an adequate sized prosthesis and a Nicks root enlargement procedure had to be performed to insert a size 23 Hancock II stented xenograft. Postoperative recovery was uneventful, with satisfactory function of the aortic bioprosthesis (peak pressure gradient of $16 \mathrm{~mm} \mathrm{Hg}$ ) at discharge echocardiography.

Comment. Moving from the observation of longer duration of hand-sewn aortic homografts in the aortic root when compared to stent-mounted aortic valve homografts, ${ }^{1}$ a new generation of stentless xenograft valves has been developed that closely resemble freehand homografts in structure and technique of implantation. ${ }^{1,2}$ Owing to the ability to adapt to the aortic root in a more anatomic fashion, stentless xenografts are thought to dampen the mechanical stress to which the aortic valve leaflets are normally subjected. Inasmuch as mechanical stress has been recognized to be a major determinant of bioprosthetic failure, stentless valves are expected to be more durable than stent-mounted xenografts. ${ }^{1}$

A variety of structural and biologic factors, besides calcification, however, may affect durability of a biopros- thesis. ${ }^{4,5}$ The two cases reported herein document the occurrence of early ( $<12$ months) structural failure with the O'Brien-Angell stentless porcine xenograft. The O'Brien-Angell stentless bioprosthesis is a composite valve constructed with noncoronary leaflets obtained from three porcine valves. The leaflets are sutured together along the free edges of the aortic wall at the leaflet commissures. Preliminary results with the O'Brien-Angell stentless aortic xenograft suggest the existence of a learning curve, which tends to blunt after the first 50 implants. $^{2}$ Satisfactory early results are thereafter reported with limited need for reoperation, credited primarily to technical factors. ${ }^{2}$ Our preliminary experience with 40 O'Brien-Angell valves, out of the more than 170 aortic stentless xenograft implants, resembles that of Hvass and associates. $^{2}$ Whereas two of our early ( $<12$ months) reoperations were clearly technique-related, the two reinterventions described herein were caused by structural failure of the valve. In the first patient, tear of the porcine aortic wall support a few months after implantation, causing severe perivalvular regurgitation, could be attributed to intraoperative trauma or uneven shear stress on the valve. The fibrous tissue overgrowth restricting leaflet opening in the second patient is a phenomenon well described with the standard stented xenograft valves and suggests the involvement of biologic reactions in the host. ${ }^{4,5}$ Replacement of the xenograft valves was not exceedingly challenging, although in one patient the aortic anulus had to be enlarged because of scarring of the aortic root.

Early dysfunction with the O'Brien-Angell freehand stentless aortic xenografts may occur as a result of structural valve failure or fibrous tissue overgrowth. Given the existence of alternative substitutes for replacement of the diseased aortic valve, close scrutiny of the early and late shortcomings of stentless xenografts is still advised.

\section{REFERENCES}

1. David TE, Pollick C, Bos J. Aortic valve replacement with stentless porcine aortic bioprosthesis. J Thorac Cardiovasc Surg 1990;99:113-8.

2. Hvass U, Chate1 D, Assayag P, et al. The O'Brien-Angell stentless porcine valve: early results of 150 implants. Ann Thorac Surg 1995;60:\$414-7.

3. O'Brien MF. The CryoLife-O'Brien composite aortic stentless xenograft: surgical technique of implantation. Ann Thorac Surg 1995;60:S410-3.

4. Milano A, Bortolotti U, Mazzucco A, et al. Performance of the Hancock porcine bioprosthesis following aortic valve replacement: considerations based on a 15-year experience. Ann Thorac Surg 1988;46:216-22.

5. Bortolotti U, Gallucci V, Casarotto D, Thiene G. Fibrous tissue overgrowth on Hancock mitral xenografts: a cause of late prosthetic stenosis. Thorac Cardiovasc Surg 1979;27: $316-8$. 